\title{
Biomass Fast Pyrolysis Energy Balance of a 1kg/h Test Rig
}

\author{
K Atsonios, ${ }^{*}, 2$, K.D. Panopoulos ${ }^{1}$, A.V. Bridgwater ${ }^{3}$, Em. Kakaras ${ }^{1,2}$ \\ ${ }^{1}$ Chemical Process and Energy Resources Institute, Centre for Research and Technology Hellas, 6th km. Charilaou - \\ Thermi Road, GR - 57001, Thermi, Thessaloniki, Greece \\ ${ }^{2}$ Laboratory of Steam Boilers and Thermal Plants, National Technical University of Athens, Heroon Polytechniou 9, \\ 15780, Athens, Greece \\ ${ }^{3}$ Aston University Bioenergy Research Group, CEAC, Birmingham B4 7ET, United Kingdom \\ e-mail: *atsonios@ certh.gr
}

Received 15 October 2015, Revised 19 November 2015, Accepted 20 November 2015

\begin{abstract}
The present paper offers a methodological approach towards the estimation and definition of enthalpies constituting an energy balance around a fast pyrolysis experiment conducted in a laboratory scale fluid bed with a capacity of 1 $\mathrm{kg} / \mathrm{h}$. Pure $\mathrm{N}_{2}$ was used as fluidization medium at atmospheric pressure and the operating temperature $\left(\sim 500^{\circ} \mathrm{C}\right)$ was adjusted with electrical resistors. The biomass feedstock type that was used was beech wood. An effort was made to achieve a satisfying $92.5 \%$ retrieval of products (dry basis mass balance) with the differences mainly attributed to loss of some bio-oil constituents into the quenching medium, ISOPAR ${ }^{\mathrm{TM}}$. The chemical enthalpy recovery for bio-oil, char and permanent gases is calculated $64.6 \%, 14.5 \%$ and $7.1 \%$, respectively. All the energy losses from the experimental unit into the environment, namely the pyrolyser, cooling unit etc. are discussed and compared to the heat of fast pyrolysis that was calculated at $1123.5 \mathrm{~kJ}$ per $\mathrm{kg}$ of beech wood. This only represents $2.4 \%$ of the biomass total enthalpy or $6.5 \%$ its HHV basis. For the estimation of some important thermo-physical properties such as heat capacity and density, it was found that using data based on the identified compounds from the GC/MS analysis is very close to the reference values despite the small fraction of the bio-oil components detected. The methodology and results can help as a starting point for the proper design of fast pyrolysis experiments, pilot and/or industrial scale plants.
\end{abstract}

\section{Keywords: Bio-oil; fast pyrolysis; beech wood; energy balance.}

\section{Introduction}

Bio-oil production by fast pyrolysis is an option for biomass pre-treatment prior to its final energetic utilization in other processes such as combustion, gasification etc. [1]. Solid biomass is converted by rapid heating in an oxygen free environment into a hot gaseous mixture of recoverable condensables in vapor and aerosol form, permanent gases, while a small fraction remains as a solid residue (char). Subsequent quenching, cooling and condensing processes allow the recovery of the liquid product known as bio-oil.

The determination of the heat of pyrolysis and the required cooling load for quenching is necessary for the deeper understanding of the process, the required heat for the biomass conversion to pyrolysis gas and vapors and the mechanism of its cooling. Two factors make it difficult to accurately calculate the heat balance of the system: a) the inability to derive a proper description of the fast pyrolysis reactions [2] together with b) the complexity of the pyrolysis vapor composition, as many of its components are unknown in the gaseous condition [3]. Moreover, there is very little literature on the problems and methodology to follow on performing an energy balance around a fast pyrolysis unit. This study is illustrative of the above issues - with the inherent limitations that are always present when using small equipment or having a mass balance that is not $100 \%$ closed.

Additionally, few studies in the literature have been dedicated to the calculation of the heat of fast pyrolysis. Haseli et al. [4] made a literature survey on this issue and noted that there is a large scatter in the reported values for this parameter. For various biomass types, the specific heat of pyrolysis on a dry basis has been measured between 207 $434 \mathrm{~kJ} / \mathrm{kg}$ [5] and 385-646 kJ/kg at $400{ }^{\circ} \mathrm{C}$ [6] and 800-1600 $\mathrm{kJ} / \mathrm{kg}$ at $500{ }^{\circ} \mathrm{C}$ [7]. The calculation of heat of pyrolysis in a pilot or bench scale reactor is performed either via the energy balance calculation on the pyrolysis reactor [7], or via differential scanning calorimetry [8].

For the rough estimation of the heat of pyrolysis, avoiding conducting any experimental procedure, three different methodologies were found in the literature that can be used:

a) The first methodology suggests that the total heat requirement $Q_{\text {pyro }}$ is a sum of the sensible heat for the temperature rise of biomass to the reaction temperature $(\Delta \mathrm{Hs})$ and the heat of reaction $\left(\Delta H_{r}\right)[5]$ :

$$
\begin{aligned}
& Q_{\text {pyro }}=\Delta H_{s}+\Delta H_{r} \\
& \Delta H_{s}=\dot{m}_{\text {beech }} \cdot\left(\int_{T_{o}}^{T_{\text {reac }}} C_{p, \text { beech }} \cdot d T\right) \\
& \Delta H_{r}=\dot{m}_{\text {beech }} \cdot\left(553-3142 \cdot \mu_{\text {char }}\right)
\end{aligned}
$$

The units of biomass flow rate $\left(\dot{m}_{\text {biom }}\right)$ is in $\mathrm{kg} / \mathrm{s}$ in both equations. The heat of reaction $\left(\Delta H_{r}\right)$ is estimated based on the empirical equation of Antal [9]. This analysis was 
performed for cellulose pyrolysis, suggesting that the required heat to effect the phase change from cellulose to the pyrolysis products at the pyrolysis temperature has a strong correlation with the char yield. This equation is valid for pyrolysis temperatures between $275-510{ }^{\circ} \mathrm{C}$ and for a wide range of heat rate $\left(10^{-2}-10^{5} \mathrm{C} / \mathrm{min}\right)$. The parameter $\mu_{\text {char }}$ is the weight fraction of char coal produced. For the calculation of $\Delta H_{r}$ a rough assumption is made that the specific heat of cellulose pyrolysis (in $\mathrm{kJ} / \mathrm{kg}$ ) equals to the corresponding specific heat of total biomass pyrolysis. This can be partially justified by the fact that cellulose comprises about half of most biomass materials [9].

The specific heat capacity of the biomass $\left(C_{p, b i o m}\right)$ depends on the process temperature and varies for different types of biomass. In this study, when this approach is applied, the specific heat capacity of the biomass is calculated from the Kirov's correlation [10]. According to it, heat capacity is considered a weighted sum of the heat capacities of the constituents (moisture, fixed carbon, volatiles and ash):

$$
C_{p}=\sum_{i=1}^{n c n} w_{i} C_{p, i}=\sum_{i=1}^{n c n} w_{i}\left(a_{i 1}+a_{i 2} T+a_{i 3} T^{2}+a_{i 4} T^{3}\right)
$$

where $w_{i}$ is the weight fraction of each constituent in the biomass according to the proximate analysis and $i=1$ for moisture, 2 for fixed carbon, 3 for volatile matter and 4 for ash. More information about the values of parameters $\alpha_{i j}$ can be found in [10].

b) The second methodology is based on empirical correlations, such as the ones adopted by Boukis et al. [11] based on the study of McKeough et al. [12] that depend on the moisture $\left(\mu_{w}\right)$ and ash $\left(\mu_{\alpha}\right)$ content of the feedstock:

$$
Q_{\text {pyro }}=991.5+3392 \frac{\mu_{w}}{1-\left(\mu_{w}+\mu_{a}\right)}[k J / k g], \text { on a daf basis }
$$

or

$$
Q_{p y r o}=1332.9+3702.7 \frac{\mu_{w}}{1-\left(\mu_{w}+\mu_{a}\right)}[k J / k g], \text { on a daf basis }
$$

In both cases, the heat of pyrolysis is assumed as the sum of the heat for vapours vaporization (first addend) and the heat for water evaporation (second addend). The first equation (referring as "direct products evolution") assumes that all the reactions take place in the range of $250-350^{\circ} \mathrm{C}$, while the second one (referring as "subsequent products evolution") it is considered that the final products are formed consecutively while the reaction temperature increases from 135 - $275{ }^{\circ} \mathrm{C}$. Steam evolution occurs at $135{ }^{\circ} \mathrm{C}$, light organics at $150{ }^{\circ} \mathrm{C}$ and heavy organics at $275{ }^{\circ} \mathrm{C}$. As stated in the study of Boukis et al. [11], the temperature at which the pyrolysis products start vaporization is unknown, resulting to the development of these two different cases regarding the assumptions on the evolution of the pyrolysis process. This is a generic approach where the produced biooil is considered as a mixture of heavy and light organics and water.

c) The third methodology is based on the calculation of the difference in total enthalpy between the reactants and the products. To overcome the lack of knowledge about the thermophysical properties of the bio-oil, the simplified approach of $\mathrm{Ng}$ and Sadhukhan [13] is adopted. According to this, it is assumed that bio-oil consists of a representative composition of $1 / 4$ acetic acid $\left(\mathrm{C}_{2} \mathrm{H}_{4} \mathrm{O}_{2}\right), 1 / 4$ acetol $\left(\mathrm{C}_{3} \mathrm{H}_{6} \mathrm{O}_{2}\right), 1 / 4$ guaiacol $\left(\mathrm{C}_{7} \mathrm{H}_{8} \mathrm{O}_{2}\right)$ and $1 / 4$ water $\left(\mathrm{H}_{2} \mathrm{O}\right)$.
The present study presents a methodology for performing an energy balance of a fast pyrolysis unit, based on experimental data obtained from beech wood fast pyrolysis (typical for laboratory scale experimental work). This approach is quite different from those presented by Daugaard and Brown [7]. Here, the heat of pyrolysis is determined after the consecutive performance of heat balance calculation around the quencher and around the pyrolyser. From the first heat balance, the total enthalpy of the pyrolysis gas (i.e. the vapors products of the pyrolysis) is estimated which is used at the second heat balance for the calculation of the heat of pyrolysis. To evaluate this, several parameters were measured such as the mass flow rates of feedstock and products, their elemental analysis and heating value, temperatures in various points at the rig, the cooling water flow, etc. Several process data such as the heat inputs and outputs are reported. The results are discussed comparatively with the three approaches described above. Additionally, basic thermophysical properties such as density and specific heat capacity of the bio-oil based on the detected compounds through GC-MS analysis were evaluated and compared with corresponding values from the literature. The scope of the last aspect is to see if the detected compounds of the bio-oil, the sum of which is not more than $40 \mathrm{wt} \%$ of the total biooil, are adequate for a good estimation of the bio-oil thermophysical properties.

The energy balance is important for the design of larger units including specifications for coolers and quench units. The present paper is not intended to declare that this particular explanatory test run can serve as the actual design parameters for larger systems. The test run provides data to build and illustrate the methodology, which is rarely presented in existing literature. The experimental campaign was carried out at the $1 \mathrm{~kg} / \mathrm{h}$ rig bubbling fluid bed (BFB) fast pyrolysis reactor in the Bioenergy Research Group at Aston University [14].

\section{Description of the Test Rig}

The $1 \mathrm{~kg} / \mathrm{h}$ wood pyrolysis capacity BFB reactor is located at the Aston University Bioenergy Group and is presented schematically in Figure 1. This test rig has also been employed for experimental investigation of the fast pyrolysis process in several past studies. In spite of its small size, this unit can achieve satisfactory levels of mass balance closures (from $90 \%$ to $96 \%$ ), permitting the extraction of robust conclusions about the process [14-19].

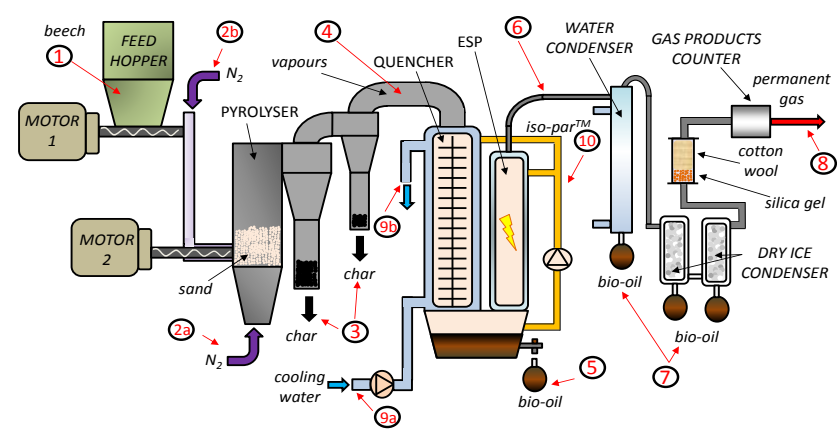

Figure $1.1 \mathrm{~kg} / \mathrm{h}$ rig test reactor scheme (not to scale).

The biomass feedstock is stored (1) in the tubular storage hopper and is dosed through a twin metering screw feeder that is coupled with a variable speed motor, into a second high speed water cooled feeding screw. Nitrogen is used as an inert gas through both feeders. The reactor is a bubbling 
fluidized bed, using nitrogen (2a) as fluidizing agent while the reactor bed initial inventory is $1 \mathrm{~kg}$ quartz sand with a particle size range from 0.16 to $0.71 \mathrm{~mm}$. Biomass feedstock is fed at the reactor pneumatically using nitrogen as carrier gas (2b). The biomass pyrolysis takes place in the atmospheric fluidized bed. The reactor is cylindrical and is separated into two regions. The first, which is the fluid gas heater, has $160 \mathrm{~mm}$ length and $76 \mathrm{~mm}$ inner diameter. The second (upper) part, where the pyrolysis process is conducted, has a length of $163 \mathrm{~mm}$ and $102 \mathrm{~mm}$ inner diameter. The wall thickness is $1.65 \mathrm{~mm}$. Char which is not reacted is separated in two consecutively heated cyclones and is collected in two char pots (3). The required heat for the pyrolysis process is provided partially by the hot fluidizing agent (2a) and by the radiative electrical resistances (external heating). In order to keep constant temperature along the reactor, the cyclones and before the quencher, this part of the rig is covered with flexible ceramic fiber blankets insulation. Externally, a thinner layer of stone wool was wrapped around them and above it, an aluminum coating for safety reasons. The vapors (4) are rapidly cooled in the quench by direct contact with an immiscible hydrocarbon, ISOPAR ${ }^{\mathrm{TM}}$, where the condensates constitute the main bio-oil (5). The quenching media, ISOPAR ${ }^{\mathrm{TM}}$, is a high boiling organic liquid of mixed iso-paraffins that is recirculated and cooled and enhances rapid temperature reduction of the pyrolysis vapors by direct contact with them. Aerosols are recovered in the wet wall electrostatic precipitator (ESP) where ISOPAR ${ }^{\mathrm{TM}}(10)$ also recirculates. The total amount of ISOPAR ${ }^{\mathrm{TM}}$ that circulates for the quenching and bio-oil recovery process was $14 \mathrm{lt}$. The ISOPAR $^{\mathrm{TM}}$ is cooled by means of cooling water $(9 \mathrm{a}, 9 \mathrm{~b})$ flowing inside the water jacketed quench. The ESP outlet vapor stream is further cooled in the two dry ice/acetone condensers at $-70^{\circ} \mathrm{C}$. The vapors that are condensed are mainly water and any residual low boiling point organic compounds $(6,7)$ which are collected separately from the main bio-oil. The water remaining in the vapor phase is completely removed by the silica gel absorbent and demisted in a cotton wool filter to maximize product recovery for mass balance purposes. The non-condensable (permanent) gases pass through a gas meter while a small portion is diverted into a micro-gas chromatograph (Micro-GC) for gas analysis.

\section{Experimental Methodology}

\subsection{Preparation Methodology}

The beech wood feedstock was firstly ground to a particle size between $0.25-2 \mathrm{~mm}$. In order to achieve a feedstock flow rate of $1 \mathrm{~kg} / \mathrm{h}$, the screw feeder was set at $170 \mathrm{rpm}$. The methodology of the mass balance calculation is based on the weighting the components that retain part of the products initially and after the end of the experiment. All of these components (oil-pots, char pots, tubes and connectors of the main components of the rig, cotton wool filter and silica gel and bed material) are therefore weighed before the start of the experimental procedure.

\subsection{Experimental Procedure}

Feeding biomass into the pyrolysis reactor began after the temperature in the fluidized reached $510{ }^{\circ} \mathrm{C}$. The fluidization started $30 \mathrm{~min}$ before the beginning of the pyrolysis process in order the reactor got the desired temperature. Setting fluidization velocity $\left(0.017 \mathrm{~m}^{3} / \mathrm{min}\right)$ three times higher than the minimum one [14], the residence time of the hot vapors from the fast pyrolysis reactor to the top of the quencher is below $1.5 \mathrm{~s}$. Furthermore, this velocity has also been tested and validated in previous studies in terms of minimization of particles entrainment. Hence it is regarded and confirmed after the experiment that no unconverted biomass is detected in char pots or in bio-oil collectors. In order to estimate the heat losses from the quencher, the temperature on the surface of the quencher was measured manually several times during the experiment. The interval analysis of the non-condensable gases was performed on-line every three minutes by a Varian CP 4900 Micro-GC. This devise has a thermal conductivity detector (TCD) and two columns (Varian CP-5A Molsieve and CP-PortaPLOT).

\subsection{Post-experiment Analysis}

The measurement of the moisture content of the bio-oils $(5,7)$ was accomplished by volumetric Karl-Fischer titration [14]. Bio-oil was collected from the tank that inter-connects the quencher and the ESP (5) and required effective separation of the ISOPAR ${ }^{\mathrm{TM}}$ and dissolved permanent gases. Three samples from each of these bio-oil retrieval points were analyzed in order to derive a representative value of their moisture content. Although this separation takes place several hours after the end of the experiment in order to secure the effective stratification of the two liquids, complete recovery of the bio-oil is not feasible due to the fact that biooil is manually extracted (small quantities of bio-oil remain to the ISOPAR ${ }^{\mathrm{TM}}$ mixture while the extracted bio-oil contains small quantities of ISOPAR ${ }^{\mathrm{TM}}$ ). The weight difference of sand before and after the experiment determines the portion of biomass that was not reacted. No sand was detected in the char pots, so it is considered that the fines entrainment from the pyrolysis reactor is negligible. A part of this portion is char that did not leave the reactor but in this study, the fuel solids that remained to the bed are considered as unconverted dried biomass in this analysis, since it is not practically recovered. This portion of biomass was 2.59 wt \% of the total biomass input (on a dry basis).

The HHV was measured using a Parr 6400 automated Isoperibol Calorimeter following the EN 14918 standard with an acceptable repeatability of $120 \mathrm{~J} / \mathrm{gr}$ and an average $2.5 \%$ uncertainty on standard reference materials samples.

Samples of the produced bio-oil were injected in a PerkinElmer Clarus 680 gas chromatograph (GC) and Clarus $600 \mathrm{~S}$ mass spectrometer (MS) with flame ionisation detector (FID) for the identification of all GC-detectable compounds. The liquid samples undergo devolatilization at $250{ }^{\circ} \mathrm{C}$ in a CDS 5200 pyrolyser close-coupled to the GCMS-FID. More details on the sample analysis of fast pyrolysis liquids with this technique can be found in [15].

\section{Results and Discussion \\ 4.1 Experimental Results}

The mass flow rate and the temperature of the fast pyrolysis unit main streams are shown in Table 1. The mass balance closure is shown in Figure 2. The mass recovery is $93.41 \%$ of the total feedstock (on a wet basis). It is considered that the bio-oil that is recovered and measured consists of the organic compounds (vapors) that are condensed in the quencher, and water. Part of this water (feed moisture) is the moisture content of the initial biomass and the rest of it (reactor water) is the water that was formed from the reactions that occur during the pyrolysis process. The permanent product gas is $2 \%$ of the total gas that exits the pyrolysis unit. The organics in the bio-oil are more than half 
the total mass input, while the reaction water (from pyrolysis) is one third of the total water in the bio-oil. As shown in Figure 2, the mass fraction of the bio-oil (including condensable organics and water) produced is $71.53 \%$ of the biomass input although the percentage of the organic compounds is $53.31 \%$.

Table 1. Time Average Flow Rate Temperature of the Fast Pyrolysis Unit Streams.

\begin{tabular}{|c|c|c|c|}
\hline $\mathbf{a} / \mathbf{a}$ & stream & $m(\mathrm{~kg} / \mathrm{h})$ & $T\left({ }^{\circ} \mathrm{C}\right)$ \\
\hline 1 & raw biomass & 0.904 & $17.2^{b}$ \\
\hline $2 \mathrm{a}$ & $\mathrm{N}_{2}$ for fluidization & 2.883 & $560.8^{a}$ \\
\hline $2 b$ & $\mathrm{~N}_{2}$ for biomass carrying & 1.225 & $17.2^{\mathrm{b}}$ \\
\hline 3 & char & 0.093 & 461.6 \\
\hline 4 & pyrolysis vapours & $4.898^{c}$ & 421.5 \\
\hline 5 & main bio-oil & 0.566 & 26.9 \\
\hline 6 & vapours quencher outlet & 4.332 & 26.2 \\
\hline 7 & secondary bio-oil & 0.072 & 26.9 \\
\hline 8 & permanent gases & 0.084 & 20.2 \\
\hline $9 \mathrm{a}$ & cooling water - in & 240.0 & 11.1 \\
\hline $9 b$ & cooling water - out & 240.0 & 15.5 \\
\hline 10 & circulated ISOPAR $^{\mathrm{TM}}$ & 525.0 & 26.9 \\
\hline $\begin{array}{l}{ }^{\mathrm{a}} \text { Thi } \\
{ }^{\mathrm{b}} \text { Ass } \\
{ }^{\mathrm{c}} \text { Incl }\end{array}$ & $\begin{array}{l}\text { ture refers after } \mathrm{N}_{2} \text { heating } \\
\text { ual to room temperature } \\
\text { rogen }\end{array}$ & \multirow{2}{*}{\multicolumn{2}{|c|}{$\begin{array}{l}\square \text { Unconverted biom } \\
\square \text { Char } \\
\square \text { Permanent gases } \\
\left\{\begin{array}{l}\square \text { Organics } \\
\square \text { Feed moisture } \\
\square \text { Reaction water } \\
\text { i- Unidentified }\end{array}\right.\end{array}$}} \\
\hline & $6.59 \% \quad 2.28 \%$ & & \\
\hline
\end{tabular}

Figure 2. Mass balance closure.

The measured elemental analysis and higher heating values of the feedstock biomass and the produced char and bio-oil are presented in Table 2.
Table 2. Feedstock and Products Characteristics.

\begin{tabular}{llll}
\hline & beech & bio-oil & char \\
\hline $\mathrm{HHV}_{\mathrm{db}}(\mathrm{MJ} / \mathrm{kg})$ & 19.8 & 20.6 & 28.3 \\
$\mathrm{C}$ (wt.\% d.b.) & 49.35 & 46.19 & 75.88 \\
$\mathrm{H}$ (wt.\% d.b.) & 6.25 & 7.91 & 3.38 \\
$\mathrm{~N}$ (wt.\% d.b.) & 0.05 & 0.22 & 0.36 \\
$\mathrm{O}$ (wt.\% d.b.) & 44.40 & 45.69 & 20.38 \\
ash (wt.\% d.b.) & 0.65 & 0.00 & 1.78 \\
moisture (wt.\%) & 12.08 & 25.46 & - \\
\hline
\end{tabular}

The time-average composition of the permanent gas is shown in Table 3. Nitrogen and water are excluded from permanent gas composition and only light gases and other organic compounds detected by the GC-MS are included.

Table 3. Permanent Gas Composition ( $m o l \%, \mathrm{~N}_{2}$ and water free basis) $)^{I}$.

\begin{tabular}{ll}
\hline $\mathrm{H}_{2}$ & $2.35 \%$ \\
$\mathrm{CO}$ & $36.44 \%$ \\
$\mathrm{CO}_{2}$ & $29.23 \%$ \\
Methane & $15.19 \%$ \\
Ethene & $3.36 \%$ \\
Ethane & $4.48 \%$ \\
Propene & $3.85 \%$ \\
Propane & $5.04 \%$ \\
n-Butane & $0.07 \%$ \\
\hline probably there are several more volatile hydrocarbons with even lower concentration
\end{tabular}
that are not measured like benzene

The HHV of the product gas was calculated at $16244 \mathrm{~kJ} / \mathrm{kg}$ (on a nitrogen and water free basis). The percentage of the 24 most frequently detected compounds in the bio-oil from GC-MS analysis along with the corresponding specific heat capacity, density and latent heat of vaporization are shown in Figure 3. It is underlined that less than $40 \%$ of the components of the organic part of the bio-oil (water content excluded) are detectable by GCMS (Figure 3a). However, the thermochemical properties like density $(\rho)$ and specific heat capacity $\left(C_{p}\right)$ of each component (data obtained from runs performing with the ASPEN Plus taking advantage its wide databank) are similar; the average

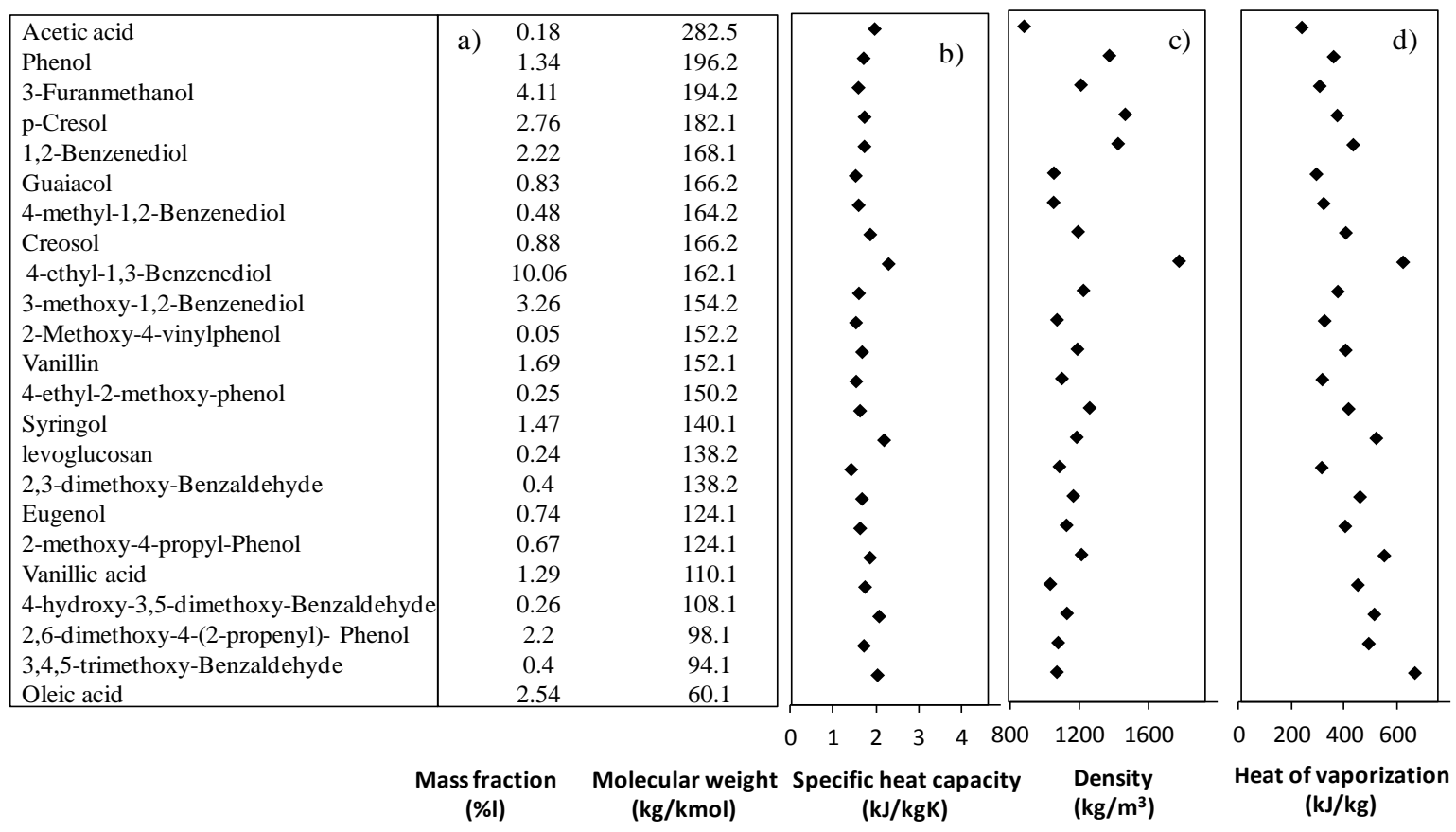

Figure 3. GC-MS analysis of the organic part of bio-oil organic part: a) mass fraction of the detectable species with their corresponding molecular weight, b) specific heat capacity at STP, c) density at STP and d) heat of vaporization at STP. 
density is calculated as $1300 \mathrm{~kg} / \mathrm{m}^{3}$ with standard deviation $190 \mathrm{~kg} / \mathrm{m}^{3}$ and the average specific heat capacity as 1.84 $\mathrm{kJ} / \mathrm{kg} \cdot \mathrm{K}$ with standard deviation $0.22 \mathrm{~kJ} / \mathrm{kg} \cdot \mathrm{K}$ (Figure $3 \mathrm{~b}$ and $3 \mathrm{c})$. This allows assuming that the organic part of the bio-oil has the abovementioned thermodynamic properties, assuming that the corresponding properties of the rest of organic compounds that are not detectable are near to the values above.

Taking into account the water content in the bio-oil $(25.5 \%)$, the basic average thermodynamic properties of the bio-oil according to this approach are presented in Table 4 and compared with the corresponding values based on simplified approach of $\mathrm{Ng}$ and Sadhukhan [13] (see Introduction) and representative values from the literature $[22,23,24]$. The selected reference values that are used for comparison are representative and indicative from pyrolysis runs using biomass with similar properties (woody biomass) in the same conditions $\left(\sim 500{ }^{\circ} \mathrm{C}\right.$ at 1 atm). The bio-oil thermodynamic properties estimation calculations were performed in ASPEN Plus ${ }^{\mathrm{TM}}$ using the Peng-Robinson equation of state [20] as the most proper property method for such systems [21]. The comparison reveals the divergence of the two methods in the calculation of all the main thermodynamic properties $\left(C_{p}, \rho\right.$ and HHV) with the method based on the GC-MS analysis to be more close to the values that are found in the literature. Furthermore, both the two methods overestimate the HHV of the bio-oil, compared to the measured value (see Table 2). However, they are close to the upper bound of the range from the reference values. From this analysis, it is concluded that the restricted identification of bio-oil composition through GC-MS analysis is a good approach for the estimation of bio-oil specific heat capacity and density but the heating value calculation is significantly different from the value derived from the elemental analysis, which is considered as an accurate methodology.

Table 4. Thermophysical Properties of Bio-oil, According to Two Approaches for Bio-oil Composition.

\begin{tabular}{lccc}
\hline & $\begin{array}{c}\text { based on } \\
\text { GC-MS } \\
\text { composition }\end{array}$ & $\begin{array}{c}\text { simplified } \\
\text { approach } \\
{[\mathbf{1 3}]}\end{array}$ & $\begin{array}{c}\text { reference } \\
\text { values } \\
{[\mathbf{2 2 , 2 3 , 2 4 ]}}\end{array}$ \\
\hline $\begin{array}{l}\text { Specific heat capacity, } \\
\mathrm{kJ} / \mathrm{kg} \cdot \mathrm{K}\end{array}$ & 2.48 & 1.87 & $2.43-3.20$ \\
$\begin{array}{l}\text { Density, } \mathrm{kg} / \mathrm{m}^{3} \\
\text { Higher heating value } \\
\text { (dry basis), MJ/kg }\end{array}$ & 1206 & 998.7 & 1200 \\
\hline
\end{tabular}

The streams characteristic that are used for the energy balance calculation are summarized in Table 1 (with numbers relating to Figure 1). $70 \%$ of the total $\mathrm{N}_{2}$ gas is used as fluidizing medium whereas the rest of it as carrier and purge gas for the feedstock. $11.3 \%$ of the total bio-oil on a wet basis is not condensed in the quencher or the ESP and is collected in the oil pots and the water and dry-ice condensers. $2.77 \%$ of the total feed, that is mainly water, is collected in the cotton wool and silica gel.

\subsection{Product enthalpy calculation}

The total enthalpy $\Delta H_{t, i}$ of the component $i$ (e.g. char, bio-oil, gas mixture) is calculated by:

$$
\Delta H_{t, i}=\Delta H_{f, i}+\Delta H_{(T) s, i}=\sum_{j=1}^{N} n_{r, j} \bar{h}_{f, j}^{o}+\left(T-T_{0}\right) \cdot \sum_{j=1}^{N} n_{r, j} C_{p, j}, \text { in }\left[\mathrm{kW}_{\mathrm{th}}\right]
$$

Where $\Delta H_{f, i}$ is the enthalpy of formation at the reference conditions $\left(25^{\circ} \mathrm{C}, 1 \mathrm{~atm}\right)$ and $\Delta H_{(T) s, i}$ is the sensible enthalpy required to certain temperature $T$. The enthalpy of formation of the non-conventional fuel can be calculated by:

$$
\sum_{i=1}^{N} m_{r e, i} \bar{h}_{f, r e, i}^{o}=\sum_{i=1}^{M} m_{p r, i} \bar{h}_{f, p r, i}^{o}+H H V_{r e} \sum_{i=1}^{N} m_{r e, i} \text {, in }\left[\mathrm{kW}_{\mathrm{th}}\right]
$$

where $m_{r e, i}$ and $m_{p r, i}$ are the mass flow rate of the component $\mathrm{i}$ of the reactants and the products, respectively. In particular, the calculation of enthalpy of formation of the beech, bio-oil and char, which only the elemental composition and the $\mathrm{HHV}$ are known, is based on their combustion reaction:

$$
\mathrm{C}_{x} \mathrm{H}_{y} \mathrm{O}_{z} \mathrm{~N}_{i}+\left(x+\frac{y}{4}-\frac{z}{2}\right) \mathrm{O}_{2} \rightarrow x \mathrm{CO}_{2}+\frac{y}{2} \mathrm{H}_{2} \mathrm{O}+\frac{i}{2} \mathrm{~N}_{2}
$$

Hence Eq. (8) is rewritten in Eq. (10):

$$
\begin{aligned}
& (12 x+y+6 z+28 i) \bar{h}_{f, C_{x} H_{y} O_{z} N_{i}}^{o}= \\
& =44 x \bar{h}_{f, C O_{2}}^{o}+9 y \bar{h}_{f, H_{2} O}^{o}+14 i \bar{h} \bar{h}_{f, N_{2}}^{o}-16\left(x+\frac{y}{4}-\frac{z}{2}\right) \bar{h}_{f, O_{2}}^{o}+H H V_{d a f} \\
& \Rightarrow \bar{h}_{f, C_{x} \mathrm{H}_{y} \mathrm{O}_{z} \mathrm{~N}_{i}}^{o}=44 x \bar{h}_{f, \mathrm{CO}_{2}}^{o}+9 y \bar{h}_{f, \mathrm{H}_{2} \mathrm{O}}^{o}+H H V_{d a f}
\end{aligned}
$$

where $\bar{h}_{f, \mathrm{CO}_{2}}^{o}=-8943.2 \mathrm{~kJ} / \mathrm{kg}$ and $\bar{h}_{f, \mathrm{H}_{2} O}^{o}=-15879.4 \mathrm{~kJ} / \mathrm{kg}$ the standard specific enthalpy of formation for $\mathrm{CO}_{2}$ and $\mathrm{H}_{2} \mathrm{O}$ respectively. The standard enthalpy of formation for $\mathrm{N}_{2}$ and $\mathrm{O}_{2}$ are zero. The enthalpies are summarized in Table 5:

Table 5. Enthalpies and Specific Enthalpies of the Pyrolysis Process.

\begin{tabular}{lccc}
\hline & $\begin{array}{c}\text { enthalpy } \\
\boldsymbol{\Delta} \boldsymbol{H}_{\boldsymbol{i}}, \mathbf{k W}\end{array}$ & $\begin{array}{c}\text { specific enthalpy } \\
\boldsymbol{h}_{\boldsymbol{i}}, \mathbf{~ k J} / \mathbf{k g}\end{array}$ & $\begin{array}{c}\boldsymbol{\%} \\
\boldsymbol{\Delta} \boldsymbol{H}_{\boldsymbol{f} \text {,beech }}\end{array}$ \\
\hline$\Delta H_{\text {, beech }}$ & 10.405 & 41445 & 100.0 \\
$\Delta H_{\text {, unconverted }}$ & 0.237 & 41445 & 2.3 \\
$\Delta H_{f, \text { gas }}$ & 0.734 & 21694 & 7.1 \\
$\Delta H_{s, \text { gas }}$ & 0.002 & 1 & 0.02 \\
$\Delta H_{f, \text { bio-oil }}$ & 6.722 & 39070 & 64.6 \\
$\Delta H_{s, \text { bio-oil }}$ & $3 \mathrm{E}-04$ & 2 & $3 \times 10^{-3}$ \\
$\Delta H_{c w}$ & 1.233 & 18 & 11.8 \\
$\Delta H_{f, \text { char }}$ & 1.507 & 58043 & 14.5 \\
$\Delta H_{\text {s, char }}$ & 0.033 & 1278 & 0.3 \\
\hline
\end{tabular}

The ratio of the chemical enthalpies each of the three products (bio-oil, char and permanent gases) to the feedstock enthalpy of formation represents the chemical enthalpy recovery $(C E R)$ of the process:

$$
C E R_{i}=\frac{\Delta H_{f, i}}{\Delta H_{f, \text { beech }}}, i=\text { bio-oil, char, perm gas }
$$

The chemical enthalpy recovery for bio-oil, char and permanent gases is calculated $C E R_{\text {bio-oil }}=64.6 \%$, $C E R_{\text {char }}=14.5 \%$ and $C E R_{\text {perm gas }}=7.1 \%$, respectively. The sensible heat of the pyrolysis products is very small $(0.34 \%$ of the feedstock enthalpy) and can be safely neglected.

The total energy input is the solid fuel enthalpy (without taking into account the sensible heat of the preheated nitrogen flow). The heat for $\mathrm{N}_{2}$ preheating represents $5.3 \%$ of the fuel heat input. Almost $65 \%$ the total energy input is converted into chemical energy of the bio-oil. According to process simulation results performed in ASPEN Plus ${ }^{\mathrm{TM}}$ about char cooling from the pyrolysis temperature to $25^{\circ} \mathrm{C}$, the sensible heat of char is $33.2 \mathrm{~W}$ which represents only $2.2 \%$ of the total energy content of the char.

The energy balance cannot close at $100 \%$ due to the incomplete mass balance closure (at 93.4\%). The energy balance around the quencher indicates that $34.0 \%$ of the cooling load is for the gas cooling and $66.0 \%$ for the bio-oil 
condensation. The amount of heat that the quencher interchanges with the ambient cannot be calculated accurately. The ISO-PAR ${ }^{\mathrm{TM}}$ recirculation system compromises a pump, valves and tubes that make difficult the estimation of heat input/loss to the quencher. Furthermore, the heat losses from the bio-oil tank are not time-steady because of the continuous increase of the bio-oil content. This effect is illustrated in Figure 4: the cooling water outlet, the water jacket and the circulating ISOPAR ${ }^{\mathrm{TM}}$ temperatures increase during the experimental procedure and part of that heat is lost to the ambient. This amount of the released heat is not steady as it depends on the heat accumulation around the walls of the quencher, the bio-oil tank and the ESP up to a certain time instant when their temperatures are stabilized. In this time period, the amount of heat that the abovementioned streams obtain from the biooil cooling is equal to the released heat to the environment.

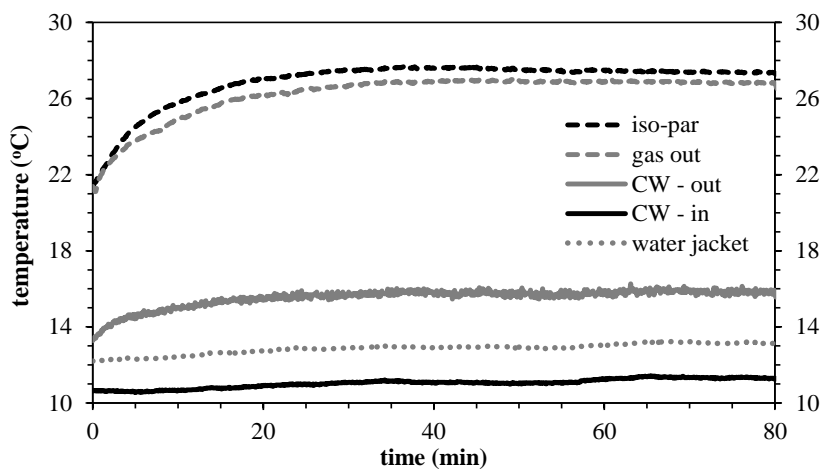

Figure 4. Evolution of the temperature of several streams in the quench.

A simplified scheme of the total process is illustrated in Figure 5, where the boundaries of the energy balance calculation are identified. The produced gas from the pyrolyser (pyrogas) comprises of the produced vapors, the steam that is coming from the fuel moisture as well as the reaction water, and mainly the inert gas $\left(\mathrm{N}_{2}\right)$. As it is seen in Table 1, the pyrolysis vapors temperature before the quencher (4) is less than the pyrolysis temperature $\left(510^{\circ} \mathrm{C}\right)$. This difference is due to heat losses $\left(Q_{p 2, l o s s}\right)$ and heat absorption in secondary cracking reactions and is taken into account in the energy balance of the system. Taking into account that nitrogen dominates at the gas stream outlet of the pyrolyser the specific heat capacity for the pyrolysis gas can be estimated $C_{p, \text { pyrogas }} \approx 1 \mathrm{~kJ} / \mathrm{kg} \cdot \mathrm{K}$. Hence, the $Q_{p 2, \text { loss }}$ is estimated at around $0.17 \mathrm{~kW}_{\text {th }}$.

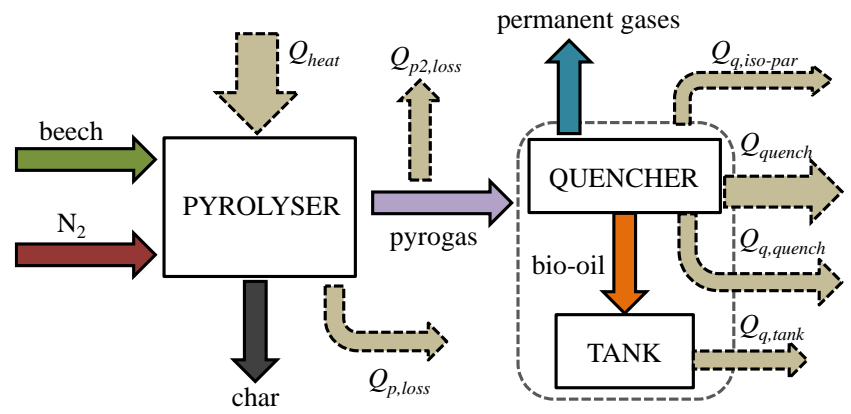

Figure 5. Energy balance configuration.

The energy balance around the pyrolyser can be expressed as:

$$
\begin{aligned}
& \Delta H_{t, N_{2}}+\Delta H_{t, \text { beech }}+Q_{\text {heat }}=\Delta H_{t, p y r o g a s}+\Delta H_{t, \text { char }}+Q_{p, \text { loss }} \Rightarrow \\
& \Delta H_{f, \text { beech }}=\Delta H_{t, \text { pyrogas }}+\Delta H_{f, \text { char }}+\Delta H_{s, \text { char }}-\underbrace{\left(Q_{\text {heat }}-Q_{p, \text { loss }}\right)}_{Q_{p y r o}}
\end{aligned}
$$

The boundaries of this energy balance are shown in the left part of the scheme in Figure 5. From eq. (12) it is clear that the heat of pyrolysis $Q_{\text {pyro }}$, can be calculated provided that the total enthalpy of pyrolysis gas $\Delta H_{t, \text { pyrogas }}$ is known. The enthalpy of the latter can be approached by the energy balance around the quench (Figure 6).

Special attention is paid to the estimation of the heat losses at the quench, $Q_{q \text {,loss }}$. This comprises the heat that is released from the surface of the cooling system (quencher, bio-oil tank and ESP) and from the ISOPAR ${ }^{\mathrm{TM}}$ circulation:

$$
Q_{q, \text { loss }}=Q_{q, q u e n c h}+Q_{q, \text { tank }}+Q_{q, \text { iso-par }}
$$

The mean measured temperature on the surface of the quencher is $15.3^{\circ} \mathrm{C}$. Taking into account a mean room temperature $17.7^{\circ} \mathrm{C}$ and the total surface area of the quencher is $A_{\text {quench }}=P \cdot \ell=400 \cdot 900=369 \cdot 10^{3} \mathrm{~mm}^{2}$ (where $P$ is the perimeter and $\ell$ the length of the quencher, respectively), the heat that enters the quencher from the environment through the walls is estimated at $Q_{q, q u e n c h}=-4.43 \mathrm{~W}$ which represents the $0.4 \%$ of the total cooling load of the quencher.

The $Q_{q, q u e n c h}$ cannot be calculated accurately because the heat source (bio-oil produced) increases linearly in the tank, affecting the mean internal temperature. Considering that the tank surface area is $A_{\text {tank }} \approx 100 \cdot 10^{3} \mathrm{~mm}^{2}$ approximately and making a rough assumption of a mean bio-oil temperature equal to the mean circulating ISOPAR ${ }^{\mathrm{TM}}$ (quite reasonable as the circulating mass of ISOPAR ${ }^{\mathrm{TM}}$ is 10 times greater than the maximum bio-oil collected in the tank), the heat losses from the bio-oil tank to the ambient are estimated $Q_{q, \text { tqnk }} \approx$ 5W ( $0.4 \%$ of the $\left.Q_{c w}\right)$.

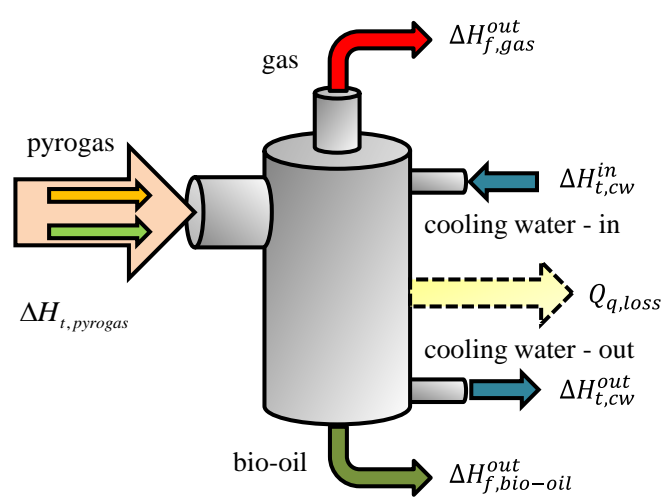

Figure 6. Energy balance around the quench.

As far as the ISOPAR ${ }^{\mathrm{TM}}$ is concerned, this amount of heat can be calculated by:

$$
\begin{aligned}
& d Q=Q_{i s o-p a r} d t=m_{i s o-p a r} C_{p} d T \Rightarrow Q_{i s o-p a r} \Delta t=M_{i s o-p a r} C_{p} \Delta T \\
& \Rightarrow Q_{i s o-p a r}=\frac{M_{i s o-p a r} C_{p}}{t_{i}-t_{i-1}}\left(T_{i s o-p a r, i}-T_{i s o-p a r, i-1}\right)
\end{aligned}
$$

where $M_{\text {iso-par }}$ and $C_{p \text {,iso-par }}$ are the total quantity of the ISOPAR $^{\mathrm{TM}}$ that recirculates and the ISOPAR $^{\mathrm{TM}}$ heat capacity, respectively. $0.014 \mathrm{~m}^{3}$ of ISOPAR ${ }^{\mathrm{TM}}$ was inserted in the circulation system of the quencher, so $M_{\text {iso-par }}=10.5 \mathrm{~kg}$. Assuming again $C_{\text {p,iso-par }} \approx 1 \mathrm{~kJ} / \mathrm{kg} \cdot \mathrm{K}$ the average $Q_{q \text {,iso-par }}$ is calculated equal to $0.05 \mathrm{~kW}$ ( $4.0 \%$ of the $\mathrm{CW}$ cooling load). 
According to the above-mentioned approaches, the total heat losses in the quench is estimated at $Q_{q, \text { loss }} \approx 0.05 \mathrm{~kW}_{\text {th }}$ representing the $0.5 \%$ of the total enthalpy input. Therefore the exact heat loss estimation has a negligible effect on performing an energy balance around the pyrolysis unit (and despite the small size of the pyrolysis unit). Hence the energy balance equation around the quench is:

$$
\begin{aligned}
& \Delta H_{t, p y r o g a s}+\Delta H_{t, c w}^{\text {in }}=\Delta H_{t, g a s}^{\text {out }}+\Delta H_{t, \text { bio-oil }}^{\text {out }}+\Delta H_{t, c w}^{\text {out }}+Q_{q, \text { loss }} \Rightarrow \\
& \Delta H_{t, \text { pyrogas }}=\Delta H_{f, g a s}^{\text {out }}+\Delta H_{f, \text { bio-oil }}^{\text {out }}+\Delta H_{s, c w}+Q_{q, \text { loss }}
\end{aligned}
$$

From the calculations, $\Delta H_{t, \text { pyrogas }}=8.91 \mathrm{~kW}$ or $h_{\text {pyrogas }}=6548$ $\mathrm{kJ} / \mathrm{kg}$. Knowing the enthalpy of the pyrolysis gas enables the calculation of the total enthalpy of the vapors that are in the pyrolysis gas. The following diagram (Figure 7) depicts the enthalpy distribution along the four steps of the process.

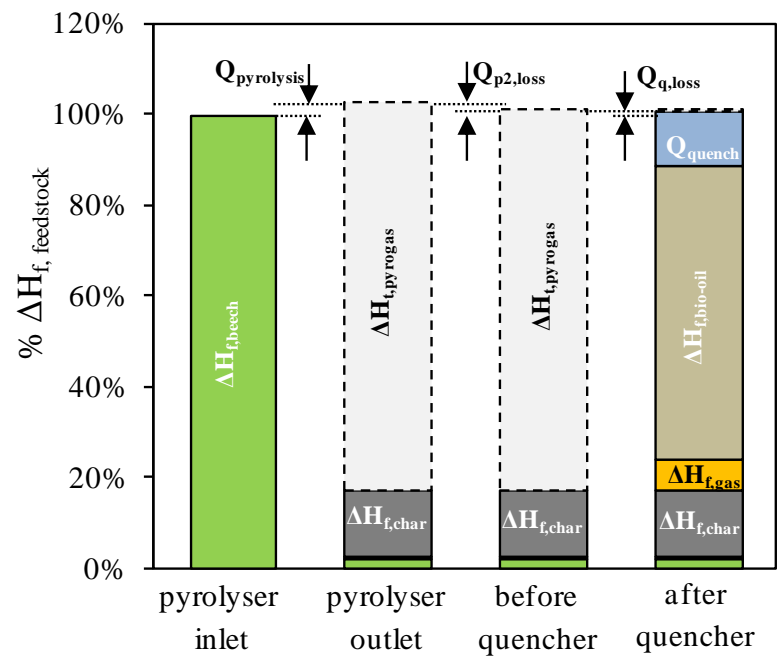

Figure 7. Enthalpy diagram along the three steps of the pyrolysis process.

From eq. (12) it is calculated that $Q_{p y r o}=0.282 \mathrm{~kW}$ which represents $2.7 \%$ of the biomass enthalpy input or $6.5 \%$ on a $H H V$ basis. The specific enthalpy is $1123.5 \mathrm{~kJ}$ per $\mathrm{kg}$ of raw biomass input. As stated before, the $H H V$ measurements had an accuracy of $\pm 0.12 \mathrm{MJ} / \mathrm{kg}$. Varying the $H H V$ of the three materials by $\pm 0.12 \mathrm{MJ} / \mathrm{kg}$, the resulted heat of pyrolysis can be from 949.5 to $1297.5 \mathrm{~kW}_{\text {th }}\left( \pm 174 \mathrm{~kW}_{\text {th }}\right)$. In other words, the reported value may be $\pm 15.5 \%$ different. This divergence that is due to the error in $H H V$ measurements which can be regarded as considerable. Future similar measurements with more accurate instruments and performing the pyrolysis test in a larger unit where the mass imbalance will be even smaller will conclude to results with less uncertainty.

Another parameter that was assumed and not measured is the specific heat capacity of the pyrogas $(1 \mathrm{~kJ} / \mathrm{kgK})$. This assumption is based on the fact that the major component of the pyrolysis gas that exits the pyrolyser is nitrogen. From a sensitivity analysis on the variation of pyrogas heat capacity it is revealed that the value of enthalpy of pyrolysis varies by $7 \%$ when the specific heat capacity varies by $10 \%(0.9$ to 1.1 $\mathrm{kJ} / \mathrm{kgK}$ ). A more detailed analysis on the calculation of the pyrogas specific heat capacity will lead to more accurate energy balance calculations.

Comparing this value with the corresponding values from the three approaches that were presented in the introduction (see Table 6), the expected underestimation is clear. It should be pointed out that a percentage of the products enthalpy is not identified due to the mass balance closure at $93.4 \%$. Therefore, the difference between the experimentally measured enthalpy value and the predicted values by the four approaches is lower than the reported ones in Table 6. Furthermore, the methodology of a typical biooil composition can address an estimation of the heat of pyrolysis that differs considerably from the corresponding experimental value.

Table 6. Comparison of Measured and Calculated Heat of Pyrolysis.

\begin{tabular}{lccc}
\hline Approaches & $\mathbf{k W}_{\text {th }}$ & $\mathbf{k J} / \mathbf{k g}_{\text {beech }}$ & $\mathbf{\%}$ \\
\hline Experimental (this study) & $0.28 \pm 0.042$ & $1123.5 \pm 174$ & - \\
$\Delta H_{s}+\Delta H_{r}[\mathbf{9 ]}$ & 0.29 & 1158.1 & -3.1 \\
Boukis 1 [11] & 0.37 & 1454.4 & -29.5 \\
Boukis 2 [11] & 0.34 & 1359.6 & -21.0 \\
Typical bio-oil composition [13] & 0.20 & 813.0 & 27.6 \\
\hline
\end{tabular}

Having calculated the energy balance around the quenching process, some additional conclusions can also be derived. The cooling load for nitrogen (inert) gas cooling is:

$\Delta H_{s, N_{2}}^{\text {in }}-\Delta H_{s, N_{2}}^{\text {out }}=m_{N_{2}} C_{p, N_{2}}\left(T_{\text {in }}-T_{\text {out }}\right)=0.48 \mathrm{~kW}$

Reducing the sensible heat for permanent gases and heat losses in the quencher, the rest of the cooling load (i.e. 0.71 $\mathrm{kW}$ ) is for the organic vapours condensation for the bio-oil production. Using the thermodynamic tool ASPEN Plus ${ }^{\mathrm{TM}}$, the required cooling duty for the bio-oil temperature drop from $421.5^{\circ} \mathrm{C}$ to $26^{\circ} \mathrm{C}$ (the GC-MS analysis is assumed for the bio-oil composition) is calculated equal to $0.34 \mathrm{~kW}$. A representation of the contribution of each factor to the quenching process is shown in Figure 8. It is clear that around $40 \%$ of the required cooling load through the cooling water is for the cooling of the inert gas (nitrogen). Following the simplified methodology of determining the bio-oil composition with the 23 known organic compounds normalized to unity, it is concluded that $17.9 \%$ of the total cooling load is used for the organics condensation and cooling, whereas $7.1 \%$ is for water condensation.

According to the thermodynamic calculations performed with ASPEN Plus ${ }^{\mathrm{TM}}$, the heat of evaporation of the organic compounds mixture (excluding water water) is $808.6 \mathrm{~kJ} / \mathrm{kg}$, whereas the range of the latent heat of evaporation of each component ranges $230-670 \mathrm{~kJ} / \mathrm{kg}$ (see Figure $3 \mathrm{~d}$ ). The corresponding heat of bio-oil evaporation as it is defined by the organic compounds identified by GC-MS and the moisture content is $1312.9 \mathrm{~kJ} / \mathrm{kg}$. It is clear that among the identified compounds, there is no representative component for the latent heat estimation and the moisture content plays important role in the bio-oil evaporation heat. The bubble point of the bio-oil is calculated at $92.2^{\circ} \mathrm{C}$ and the dew point at $303.4{ }^{\circ} \mathrm{C}$.

The specific enthalpy for bio-oil (both organics and water) condensation is estimated at $3909.1 \mathrm{~kJ} / \mathrm{kg}_{\text {bio-oil. }}$ Taking also into account the cooling load that is lost due to various factors, there is a considerable portion that is needed for heat balance closure around the quenching system and remains unidentified. Part of it may be contributed to the inconsistency of the assumption about bio-oil composition that is taken, or inaccuracy in heat losses calculations. However, one part of it is utilized for the removal of the heat derived from the exothermic reactions that occur during quenching for example, previous studies reported that esterification, etherification [23] and polymerization [25] take place during bio-oil condensation. This amount of heat 
load is around $8 \%$ of the biomass heat input on $H H V$ basis, suggesting a decrease of the bio-oil heating value during the pyrogas cooling and bio-oil transformation, regardless of any inconsistencies at the calculations.

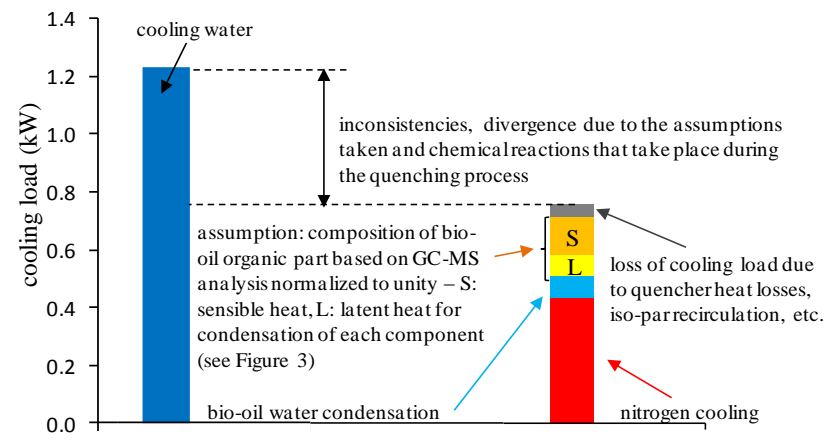

Figure 8. Heat balance distribution in the quench system.

It should be pointed out that in an industrial system, flue gases derived from the combustion of the non-condensable gases might be used as carrier gas instead of nitrogen. This fact may differentiate the heat balance distribution presented in Figure 8. Nevertheless, in performing a generic energy balance for the flash pyrolysis step the experimental work using $\mathrm{N}_{2}$ is chosen as an option to avoid having to unscramble the mixed result from the dissipated heats of both combustion and pyrolysis if $\mathrm{O}_{2}$ containing gases were to be used.

\section{Conclusions}

A mass and energy balance of a fast pyrolysis process based on experimental data shows that knowing the product yields and their composition, the efficiency of the process can be satisfactorily calculated. The chemical enthalpy recovery for bio-oil, char and permanent gases is calculated $C E R_{\text {bio-oil }}$ $=64.6 \%, C E R_{\text {char }}=14.5 \%$ and $C E R_{\text {perm gas }}=7.1 \%$, respectively. Special effort was paid to the estimation of the heat of pyrolysis of the process. Due to the mass imbalance and the difficulty to assign the heat loss along the process and especially around the quench, the calculated value lacks accuracy. Nevertheless, the specific heat of pyrolysis was calculated to be $1123.5 \mathrm{~kJ} / \mathrm{kg}_{\text {feedstock }}$ which is within the range of the corresponding values reported in the literature. After the heat balance calculation around the quench, it was revealed that the majority of the required cooling load is for inert gas cooling, while a number of exothermic reactions inevitably take place during the quenching that further reduce the heat capacity of the bio-oil produced.

\section{Acknowledgements}

The research leading to this publication has received funding from the European Union Seventh Framework Programme (FP7/2007-2013) under grant agreement $n^{\circ} 284498$ BRISK.

$\begin{array}{ll}\text { Nomenclature } \\ A & \text { surface area, } \mathrm{mm}^{2} \\ C E R & \text { chemical enthalpy recovery, \% } \\ C_{p} & \text { heat capacity, } \mathrm{kJ} / \mathrm{kg} \cdot \mathrm{K} \\ H & \text { enthalpy, } \mathrm{kW} \\ h & \text { specific enthalpy, } \mathrm{kJ} / \mathrm{kg} \\ H H V & \text { Higher Heating Value, } \mathrm{kJ} / \mathrm{kg} \\ \ell & \text { length, m } \\ M & \text { mass quantity, } \mathrm{kg} \\ m & \text { mass flow, } \mathrm{kg} / \mathrm{s} \\ M W & \text { molecular weight, } \mathrm{kg} / \mathrm{kmol}\end{array}$

$n$ molar flow, $\mathrm{kmol} / \mathrm{s}$

$q \quad$ specific heat stream, $\mathrm{kJ} / \mathrm{kg}$

$Q \quad$ heat stream, $\mathrm{kW}$

$P \quad$ perimeter, $\mathrm{m}$

$T$ temperature, ${ }^{\circ} \mathrm{C}$

$t$ time, $\min$

Greek letters

$\mu \quad$ mass fraction, $\mathrm{kg} / \mathrm{kg}$

$\rho$ density, $\mathrm{kg} / \mathrm{m}^{3}$

Subscripts

biom biomass

char fixed carbon content

CW cooling water

daf dry ash free

$d b \quad$ dry basis

$f \quad$ formation

pr product

pyro pyrolysis

$q \quad$ quenching system (quencher, bio-oil tank and ESP)

quench quencher

$r$ reaction

re reactive

$s \quad$ sensible heat

$t$ total

th thermal power

w moisture content

Greek letters

a ash content

\section{References}

[1] K. Braimakis, K. Atsonios, K. D. Panopoulos, S. Karellas, and E. Kakaras, "Economic evaluation of decentralized pyrolysis for the production of bio-oil as an energy carrier for improved logistics towards a large centralized gasification plant," Renewable and Sustainable Energy Reviews, 35, 57-72, 2014.

[2] D. Mohan, C. U. Pittman, and P. H. Steele, "Pyrolysis of Wood/Biomass for Bio-oil: A Critical Review," Energy \& Fuels, 20, 848-889, 2006.

[3] A. V. Bridgwater, "Review of fast pyrolysis of biomass and product upgrading," Biomass and Bioenergy, 38, 6894, 2012.

[4] Y. Haseli, J. A. van Oijen, and L. P. H. de Goey, "Modeling biomass particle pyrolysis with temperaturedependent heat of reactions," Journal of Analytical and Applied Pyrolysis, 90, 140-154, 2011.

[5] M. Van de Velden, J. Baeyens, A. Brems, B. Janssens, and R. Dewil, "Fundamentals, kinetics and endothermicity of the biomass pyrolysis reaction," Renewable Energy, 35, 232-242, 2010.

[6] F. He, W. Yi, and X. Bai, "Investigation on caloric requirement of biomass pyrolysis using TG-DSC analyzer," Energy Conversion and Management, 47, 2461-2469, 2006.

[7] D. E. Daugaard and R. C. Brown, "Enthalpy for Pyrolysis for Several Types of Biomass," Energy \& Fuels, 17, 934939, 2003/07/01 2003. 
[8] M. Stenseng, A. Jensen, and K. Dam-Johansen, "Investigation of biomass pyrolysis by thermogravimetric analysis and differential scanning calorimetry," Journal of Analytical and Applied Pyrolysis, 58-59, 765-780, 2001.

[9] M. Antal, Jr., "Biomass Pyrolysis: A Review of the Literature Part 1-Carbohydrate Pyrolysis," in Advances in Solar Energy, K. Böer and J. Duffie, Eds., ed: Springer New York, 1985, pp. 61-111.

[10] N. Y. Kirov, "Specific Heats and Total Heat Contents of Coals and Related Materials are Elevated Temperatures," BCURA Monthly Bulletin, 29-33, 1965.

[11] I. P. Boukis, P. Grammelis, S. Bezergianni, and A. V. Bridgwater, "CFB air-blown flash pyrolysis. Part I: Engineering design and cold model performance," Fuel, 86, 1372-1386, 2007.

[12] P. Mc Keough, M. Nissilhi, Y. Solantausta, D. Beckman, A. Ostman, A. Bergholm, et al., "IEA Cooperative Project D1: Biomass Liquefaction Test Facility Project," National Technical Information Service, Springfield, Virginia 1988

[13] K. S. Ng and J. Sadhukhan, "Process integration and economic analysis of bio-oil platform for the production of methanol and combined heat and power," Biomass and Bioenergy, 35, 1153-1169, 2011.

[14] M. Mos, S. W. Banks, D. J. Nowakowski, P. R. H Robson, A. V. Bridgwater, and I. S. Donnison, "Impact of Miscanthus $\mathrm{x}$ giganteus senescence times on fast pyrolysis bio-oil quality," Bioresource Technology, 129, 335-342, 2013

[15] S. W. Banks, D. J. Nowakowski, and A. V. Bridgwater, "Fast pyrolysis processing of surfactant washed Miscanthus," Fuel Processing Technology, 128, 94-103, 2014.

[16] C. E. Greenhalf, D. J. Nowakowski, A. B. Harms, J. O. Titiloye, and A. V. Bridgwater, "A comparative study of straw, perennial grasses and hardwoods in terms of fast pyrolysis products," Fuel, 108, 216-230, 2013.

[17] D. J. Nowakowski, A. V. Bridgwater, D. C. Elliott, D. Meier, and P. de Wild, "Lignin fast pyrolysis: Results from an international collaboration," Journal of Analytical and Applied Pyrolysis, 88, 53-72, 2010.

[18] C. E. Greenhalf, D. J. Nowakowski, A. B. Harms, J. O. Titiloye, and A. V. Bridgwater, "Sequential pyrolysis of willow SRC at low and high heating rates - Implications for selective pyrolysis," Fuel, 93, 692-702, 2012.

[19] M. A. Patel, M. A. S. Baldanza, V. Teixeira da Silva, and A. V. Bridgwater, "In situ catalytic upgrading of biooil using supported molybdenum carbide," Applied Catalysis A: General, 458, 48-54, 2013.

[20] D.-Y. Peng and D. B. Robinson, "A New Two-Constant Equation of State," Industrial \& Engineering Chemistry Fundamentals, 15, 59-64, 1976.

[21] AspenTech, "Physical Property Methods," vol. V7.1, ed. Burlington, MA: Aspen Technology Inc., 2009.

[22] S. Czernik and A. V. Bridgwater, "Overview of Applications of Biomass Fast Pyrolysis Oil," Energy \& Fuels, 18, 590-598, 2004

[23] A. C. Goteti, "Experimental investigation and systems modeling of fractional catalytic pyrolysis of pine," Master of Science, Georgia Institute of Technology, School of Chemical and Biomolecular Engineering, 2010 .

[24] K. Papadikis, S. Gu, and A. V. Bridgwater, "Eulerian Model for the Condensation of Pyrolysis Vapors in a Water Condenser," Energy \& Fuels, 25, 1859-1868, 2011.

[25] J. P. Diebold, "A Review of the Chemical and Physical Mechanisms of the Storage Stability of Fast Pyrolysis Bio-Oils," National Renewable Energy Laboratory, Colorado 2000. 